\title{
The Knowledge, Attitude and Practice of Exclusive Breastfeeding among Mothers in Two Semi-Urban Areas around a Baby Friendly Hospital Initiative (BFHI) Designated Hospital in Lagos State, Nigeria
}

\section{Abstract}

Background: The World Health Organization (WHO) and United Nations Children's Fund (UNICEF) initiated intensive efforts to transform hospitals into breastfeeding support centers through the Baby Friendly Hospital Initiative (BFHI). The study populations in this study were geographically located within the vicinity of a BFHI designated Hospital in Lagos, Nigeria. The aim of this study was to determine the knowledge, attitude and practice of exclusive breast feeding among mothers in two semi-urban areas around a BFHI designated hospital.

Method: Four hundred self-administered questionnaires were distributed to mothers from two semi urban areas in Surulere Local Government Area of Lagos, Nigeria to ascertain their socio demographic data, knowledge, attitude and practice of exclusive breastfeeding. Approval for the study was granted by the Ethics Committee. The respondents were chosen by simple random sampling. The questions covered socio demographic data, knowledge, attitude and the practice of exclusive breastfeeding (EBF). Collected data was analyzed and investigated for statistical associations.

Results: The knowledge, attitude and practice of exclusive breastfeeding amongst mothers in the semi urban area of Lagos, Nigeria is statistically significantly affected by their educational level and by their professional level. Those with a higher level of education were more likely to have a correct knowledge $(P<0.05)$. Religion, educa-
Titilola T. Obilade MBBS, Ph.D.

Contact information:

Titilola T. Obilade MBBS, MPH, FMCPH, MWACP, MILD, Ph.D.

Senior Education Specialist Learning Sciences and Technology 144J Smyth Hall.

Virginia Polytechnic Institute and State University.

Blacksburg, Virginia, 24061- 0488.

”' obilade@vt.edu 
tional level, professional level and number of children were statistically significant for practicing EBF for at least three months $(P<0.05)$. The belief that colostrum is not good for the baby was statistically significant for educational level and profession $(P<0.05)$. The belief that sperm could get into the breast milk was statistically significant for age, religion, ethnic group, education, profession and the number of children $(P<0.05)$. Out of all the socio demographic variables examined, educational level of the mother and the mother's professional level were the two variables that were most frequently statistically significant for knowledge, attitude and practice questions.

Conclusion: The knowledge, attitude and practice of breastfeeding are mostly affected by the education and the profession of the mother. Certain beliefs about breast milk and sperm were statistically significant across all the socio demographic data examined. Recommendations were made to increase health education targeted at correcting beliefs about colostrum and breast milk. Recommendation was also made for a reevaluation of $\mathrm{BFHI}$.

\section{Keywords}

Nigeria, Exclusive breastfeeding(EBF); Baby Friendly Hospital Initiative (BFHI); Knowledge; Attitude; Practice, Predictive Factors; Education; Socio demographic factors; Colostrum 


\section{Introduction}

The aim of the study was to determine the knowledge, attitude and practice of exclusive breastfeeding (EBF) amongst mothers living in areas around a Baby Friendly Hospital Initiative (BFHI) designated hospital in Lagos, Nigeria.

Objectives:

1. To determine the relationship between mothers' knowledge on exclusive breastfeeding and the practice of exclusive breastfeeding in two semi-urban areas of Lagos, Nigeria.

2. To determine the socio demographic predictive factors of Exclusive Breastfeeding.

3. To determine the effectiveness of the propagation of Exclusive Breastfeeding amongst mothers in areas served by BFHI designated hospitals.

Exclusive breastfeeding (EBF) is giving the child breast milk alone in the first six months of life [1]. The inclusion of water along with the breast milk is not considered EBF but if water is given as part of an oral rehydration solution, it does not negate EBF [1]. The inclusion of vitamins is still considered EBF. Studies have shown that EBF in the first six months of life decreases the risk of gastroenteritis $[2,3]$. Lactational amenorrhea is another advantage to EBF. It is not all studies that have shown a demonstrable reduction in respiratory tract infection through EBF [4]. Kramer and Kakuma's [2] review of literature showed that EBF was a protective factor in sudden infant death syndrome.

According to the 2008 Bulletin of World Health Organization (WHO), [5] the distribution of deaths due to diarrhea in low- and middle- income countries was highest in Africa. Nigeria was ranked second amongst countries with the highest mortality rate due to diarrhea [5]. The Global Health Observatory Report by WHO, 2014 reported that between the years 2000 and 2010, 700, 000 children below the age of five died before their fifth birthday [6]. Malaria, pneumonia, prematurity and diarrhea were responsible for 60 percent of the deaths. Malaria, pneumonia and diarrhea are preventable diseases. Breast milk offers protection against diarrheal and respiratory infections $[3,7,8]$. Human breast milk contains the nutrients the baby needs in the first four to six months of life $[3,8]$. It is easily digestible [8]. It is not all empirical studies that confirm a maternal and child bonding due to breastfeeding [9]. However, a 15 year cohort study of mothers in Australia showed that mothers that breastfed their children for more than four months were less likely to perpetuate child abuse and less likely to perpetuate child neglect [10]. Similarly, a study on the relationship between breastfeeding practice and attachment security did not show any attachment relationship but mothers that breastfed were observed to be more sensitive in dyadic interactions than in non-breastfeeding mothers [11]. Initiating breastfeeding immediately following birth stimulates the contraction of the uterus and reduces blood loss $[12,13]$. It is cheap and reduces health care costs [14]. This study aims at determining the socio demographic predictive factors of exclusive breastfeeding amongst mothers in a semi urban area of Lagos, Nigeria.

\section{Literature Review}

\section{Nigeria}

Nigeria is located in West Africa and bordered by the Republic of Niger to the North, the Republic of Cameroon to the East, The Republic of Benin to the West and the Atlantic Ocean to the South. The study populations for the study were from the semiurban areas of Lagos State. Lagos is the old capital of Nigeria. The population of Nigeria was 173.6 Million in 2013 [15]. The under age 5 mortality rate per 1000 live births for 2010-2015 is 122[15]. More than half of the population lived below US\$ 1.25 per day between 2007 and 2011 [16]. Although Nigeria is one of the major producers of the world's oil and the $6^{\text {th }}$ largest producer of petroleum among 
Organization of Oil Exporting Countries (OPEC), [18] Nigeria placed ninth [16] in the Under 5 Mortality Rank for 2012. In 2010, Nigeria ranked twelfth and Somali ranked first on the Under 5 Mortality Rank [17]. The Lagos University Teaching Hospital has been designated a Baby Friendly Hospital Initiative since the 90's and is located within the vicinity of the study populations. Nigeria was ranked second amongst countries with the highest mortality rate due to diarrhea [5].

\section{The Baby Friendly Hospital Initiative}

As a complement to community based efforts to protect, promote and support breastfeeding and to promulgate the code, in 1991, United Nations Children's Fund (UNICEF) and WHO began an intensive effort to transform breastfeeding practices in maternity hospitals to support breastfeeding. A UNICEF State of the World's Children in 1998, reported that before BFHI, four percent of mothers practiced EBF for the first six months. After the launching of the BFHI, there was a gradual increase in the percentage of mothers that were breastfeeding exclusively. The percentage of mothers that were breastfeeding exclusively rose from a modest 25 percent in 1991 to 40 percent in 1996 [19]. However, the 2014 State of the World's Children has shown a decline in the momentum of EBF [20]. Despite the efforts of the BFHI, the practice of EBF is still below expectations. Globally, EBF is below forty percent [21]. The current status of BFHI as outlined by UNICEF [22] shows that in West and Central Africa, Nigeria has 1147 designated BFHI facilities followed by Cote d'Ivoire with $85 \mathrm{BFHI}$ facilities. Cote d'Ivoire had a population of 20.3 million [15] while Nigeria had a population of 173.6 Million by 2013[15].

In the European continent, Sweden has the highest number of BFHI facilities with 64 [23]. The USA has 25 existing BFHI facilities [23]. China has more than $6000 \mathrm{BFHI}$ facilities [23]. The number of breastfeeding facilities may be more than the statistics reveal because the term Baby Friendly may be used only by maternity services that have passed external assessments according to the global criteria for the BFHI [23]. Through the BFHI professional health workers in maternity hospitals are trained in lactation management and support. They make a commitment to fulfil the initiative's ten steps to successful breastfeeding [23].

\section{The success of the BFHI}

When the BFHI was initiated in South Africa a survey was conducted to assess the current breastfeeding practices and the level of implementation of the ten steps to successful breastfeeding. A set of questionnaires were distributed to the hospital management and a separate questionnaire to the mothers. The managements' responses indicated that the hospitals were Baby Friendly. However, the mothers' responses indicated that the hospitals were not Baby Friendly [24]. The hospitals did not have a written breastfeeding policy, they did not have breastfeeding support groups and not all the health workers that came in contact with the mothers discussed exclusive breastfeeding with them [24].

A similar study done in Turkey to assess the hospital performance of the BFHI concluded that hospitals with excessive patient load found it difficult to provide the ten steps to BFHI. They made provisions for some of the steps of the BFHI but were not able to make provisions for all the ten steps. It was more difficult to implement the steps of the BFHI in private hospitals as clients were allowed to use pacifiers and supplements on demand [25]. At the Lagos University Teaching Hospital, Lagos (LUTH), Nigeria the hospital management has taken a unique approach to BFHI. In order to raise awareness and encourage mothers to breastfeed, LUTH holds a yearly contest to determine the LUTH best breastfed baby of the year. The contest is only open to babies that have been exclusively breastfed.

The economic benefit of breastfeeding is greater in low income households. A cohort study of exclusively breastfed infants who were receiving supplemental government assistance for Women, Infants 
and Children (WIC) showed that each infant saved $\$ 478$ in supplemental government assistance and in Medicaid [26]. Since exclusive breastfeeding leads to reduced risks of otitis media, reduced bronchiolitis, reduced necrotizing enterocolitis, reduced incidence of diarrhea, less wheezing and reduced incidence of meningitis, it translates to less hospital stay and economic savings for the family [27]. In the state of Louisiana alone, if ninety percent of all babies were exclusively breastfed for six months, the state would save over two million dollars in a year and 18 disease-related infant deaths would be prevented [28].

\section{Factors associated with exclusive breastfeeding}

A study conducted at the University of Benin Hospital Nigeria, revealed that birth weight showed significant association with exclusive breastfeeding and that maternal age and maternal educational level did not [29]. Babies that were born with a birth weight of $2.50 \mathrm{~kg}$ or more were more likely to be breastfed than babies that were born with a weight that was less than $2.50 \mathrm{~kg}$ [29]. After the BFHI was introduced at Jos University Teaching Hospital Nigeria, mothers that had secondary or post-secondary education were more likely to exclusively breastfeed but for a shorter duration [30]. Mothers that did not have a primary school education were more likely to breastfeed exclusively for a longer period.

In a cohort study in Australia, poor compliance with exclusive breastfeeding was associated with breastfeeding difficulties, mothers returning to work, introduction of a pacifier and maternal smoking [31]. A study conducted at the University Hospital, Kuala Lumpur on the socio demographic factors associated with exclusive breastfeeding showed that mothers who had decided to breastfeed before the baby was born were more likely to breastfeed. In addition, mothers that were older than 27 years, mothers that were not in paid employment, had female infants and were of Indian ethnicity were more likely to breastfeed exclusively beyond six weeks. However, parental education, primigravida status, caesarian section, late first breastfeed and length of hospital stay were not associated with failure to breastfeed exclusively [32]. Mothers that had less than nine years of schooling, mothers that had breastfeeding difficulties and mothers of Chinese descent were more like to use exclusive infant formula [32]. A separate study also confirmed that mothers that practiced exclusive breastfeeding received the knowledge on the benefits of EBF from the government hospitals through health education [33].

\section{Benefits of Exclusive Breastfeeding}

Studies have shown that exclusive breastfeeding in the first six months of life can prevent diarrheal diseases and acute respiratory diseases [3, 8, 27]. Studies conducted in Kenya showed that children that had been given other foods apart from breast milk within six months of birth were three times more likely to be underweight than children that were exclusively breastfed for six months [34]. The consequences of malnutrition are multi-pronged and the factors responsible interconnect. Several studies have also shown that stunting and wasting are better indicators of the nourishment of the child $[35,36]$. In the Kenyan study, the children that had other foods introduced before six months were also at a higher risk of wasting [34]. Wasting measures an acute occurrence of malnourishment and stunting measures a chronic measure of malnourishment [35, 36].

A study on the role of exclusive breastfeeding on atopic dermatitis was not conclusive because the studies could not exclude that the mothers had fulfilled the criteria [37]. A study conducted at the University of Ibadan Teaching Hospital, Nigeria on bloody diarrhea in children aged $6-18$ months showed that children that were no longer being breastfed had a three-fold risk of bloody diarrhea than babies that were still being breastfed when they developed diarrhea [38]. The study also showed that when children that were not breastfed had diarrhea, they were more likely to become malnourished than babies that had diarrhea when 
they were being breastfed. Exclusive breastfeeding reduces the risk of having diarrhea.

\section{Methodology}

This study was conducted within the old capital of Nigeria; Lagos State. Although Lagos State is the old capital, rural areas are scattered among the urban areas. This study was carried out in Adelabu and Ladele Dada sub districts of Akerele district in Surulere Local Government Area of Lagos State, Nigeria. Surulere Local Government Area was chosen because a Baby Friendly Hospital, Lagos University Teaching Hospital, Idi-Araba is under Surulere Local Government Area and part of the aim of this study was to find out the effectiveness of the propagation of exclusive breastfeeding in these areas. Akerele consists of five sub-districts; Adelabu, Masha, Our Lady of Fatima, Ladele Dada and Idi-Araba. The two sub districts from which the study populations were taken were Adelabu and Ladele-Dada sub districts. These two sub districts were chosen by simple random sampling.

The following formula was used to calculate the minimum sample size required.

$$
\begin{aligned}
& \mathrm{n}= \frac{\mathrm{p} \mathrm{q}}{(\mathrm{E} / 1.96)^{2}} \\
& \text { Where } \\
& \mathrm{n}=\text { Minimum sample size required } \\
& \mathrm{p}=\text { Minimum expected prevalence rate for } \\
& \quad \text { the population from which the sample is } \\
& \quad \text { taken. Minimum exclusive breastfeeding } \\
& \quad \text { prevalence } \\
&=50 \% \\
&=0.5 \\
& \mathrm{q}=1-\mathrm{p} \\
& \mathrm{E}= \\
&=0.05 \\
& \mathrm{n}= \frac{0.5 \times 0.5}{(0.05 / 1.96)^{2}} \\
&= 384
\end{aligned}
$$

For the purpose of this study, an infant was considered to be exclusively breastfed if s/he was on breast milk alone without the addition of water. The study was a descriptive study. Approval for this study was obtained by the Ethics Committee of the Lagos University Teaching Hospital. Verbal informed consent was obtained from each respondent after the nature and purpose of the study was explained to the respondent. The study did not pose any harm to the respondent. Confidentiality was maintained throughout. Pre testing of the questionnaire was done over a period of three days.

\section{Administered Questionnaire}

The questionnaire was divided into two parts consisting of a total of twenty nine questions. The first twenty five questions were compulsory and the last four questions were for those who did not breastfeed exclusively. The first nine questions were on socio demographic data and the other 20 questions were on knowledge, attitude and practice. In the questionnaire, four categories of groups were identified under professions. These were the unemployed, the skilled, the unskilled and others. Some of those who worked as skilled workers were selfemployed and had completed their education up to the tertiary level.

\section{Study Participants}

A total of 400 women between the ages of 15-49 years old who had had children were given questionnaires at home. Following informed consent, data was collected by self- administered questionnaires. The names of the respondents were not required on the questionnaires. Two trained female interviewers were employed to distribute the questionnaires. The interviewers read the questionnaire to respondents that could not read. The interviews were mainly carried out in the evenings during working days and throughout the day on weekends to ensure that the women would be at home. Each interview lasted for about 25 minutes. 
All the streets in the sub districts were numbered. These numbers were written on paper and selected by balloting. The first streets selected were used as sample areas. On each selected street, the first house was chosen by use of ballot papers. Two hundred women were interviewed from each sub district totaling 400 women. In instances where a single house had 4 women qualified to partake in the study, pieces of paper numbered one to four were shaken in a box, and the person representing the first number that was picked was administered the questionnaire. A single house could have 4 women qualified in instances where extended families were living together.

\section{Analysis}

Test of significance was done on categorical variables using the Chi-Square at a $P$ value of 0.05 . The result was presented in tables. Non responses were not included in the analysis.

\section{Results}

The largest number of respondents were in the age range of 31-35 years old 103 (28.5\%). Almost fifty percent 192 (49.4\%) of the respondents had completed their tertiary education. Skilled professions $305(81.3 \%)$ was the most predominant. Yoruba 230 (58.2\%) and Ibo 157 (39.7\%) were the most frequent ethnic groups. Almost all the respondents were married 382 (98\%). Majority of the respondents practiced Christianity 311(85.9\%). Most of the respondents had four children 107(27.1\%) followed by those who had two children 97(24.6\%).
Table 1. Socio demographic data of respondents.

\begin{tabular}{|c|c|c|}
\hline Age (In Years) & Frequency & Percent \\
\hline $18-25$ & 41 & 10.3 \\
\hline $26-30$ & 103 & 25.8 \\
\hline $31-35$ & 114 & 28.5 \\
\hline $36-40$ & 103 & 25.8 \\
\hline$>40$ & 39 & 9.8 \\
\hline Total & 400 & 100 \\
\hline Education & Frequency & Percent \\
\hline None & 5 & 1.3 \\
\hline Primary School Uncompleted & 16 & 4.1 \\
\hline Primary School Completed & 26 & 6.7 \\
\hline Secondary School Uncompleted & 13 & 3.3 \\
\hline Secondary School Completed & 137 & 35.2 \\
\hline Tertiary Education Completed & 192 & 49.4 \\
\hline Total & 389 & 100 \\
\hline Profession & Frequency & Percent \\
\hline Housewife/Unemployed & 41 & 10.9 \\
\hline Skilled & 305 & 81.3 \\
\hline Unskilled & 20 & 5.3 \\
\hline Others & 9 & 2.4 \\
\hline Total & 375 & 100 \\
\hline Ethnicity & Frequency & Percent \\
\hline Yoruba & 230 & 58.2 \\
\hline Hausa & 5 & 1.3 \\
\hline lbo & 157 & 39.7 \\
\hline Fulani & 3 & 0.8 \\
\hline Total & 395 & 100 \\
\hline Marital Status & Frequency & Percent \\
\hline Single & 4 & 1 \\
\hline Married & 392 & 98 \\
\hline Widowed & 3 & 0.8 \\
\hline Separated & 1 & 0.3 \\
\hline Total & 400 & 100 \\
\hline Religion & Frequency & Percent \\
\hline Christianity & 311 & 85.9 \\
\hline Islam & 51 & 14.1 \\
\hline Total & 362 & 100 \\
\hline No. Of Children & Frequency & Percent \\
\hline One & 51 & 12.9 \\
\hline Two & 97 & 24.6 \\
\hline Three & 85 & 21.5 \\
\hline Four & 107 & 27.1 \\
\hline Five & 35 & 8.9 \\
\hline More than five & 20 & 5.1 \\
\hline Total & 395 & 100 \\
\hline
\end{tabular}


Table 2. Breastfeeding is essential by socio demographic data.

\begin{tabular}{|c|c|c|c|c|}
\hline \multirow{2}{*}{ No. of Children } & \multicolumn{3}{|c|}{ Breastfeeding is essential } & \multirow{2}{*}{$\begin{array}{l}P \text { Value } \\
P<0.05\end{array}$} \\
\hline & Yes (\%) & No (\%) & Total (\%) & \\
\hline One & $51(100)$ & 0 & $51(13.0)$ & \\
\hline Two & $95(100)$ & 0 & $95(24.2)$ & \\
\hline Three & $85(100)$ & 0 & $85(21.6)$ & \\
\hline Four & $106(99.1)$ & $1(0.9)$ & $107(27.2)$ & \\
\hline Five & $35(100)$ & 0 & $35(8.9)$ & \\
\hline More than Five & $18(90)$ & $2(10.0)$ & $20(5.1)$ & \\
\hline Total & $390(99.2)$ & $3(0.8)$ & 393 & \\
\hline \multirow{2}{*}{ Age } & \multicolumn{3}{|c|}{ Breastfeeding is essential } & P Value \\
\hline & Yes (\%) & No $(\%)$ & Total (\%) & $P>0.05$ \\
\hline $18-25$ & $41(100.0)$ & 0 & $41(10.4)$ & \\
\hline $26-30$ & 101(100.0) & 0 & $101(25.6)$ & \\
\hline $31-35$ & $109(98.2)$ & $2(1.8)$ & $111(28.2)$ & \\
\hline $36-40$ & $101(100.0)$ & $1(1.0)$ & $102(25.9)$ & \\
\hline$>40$ & $39(100.0)$ & $0(0.0)$ & $39(9.9)$ & \\
\hline Total & $391(99.2)$ & $3(0.8)$ & 394 & \\
\hline \multirow{2}{*}{ Religion } & \multicolumn{3}{|c|}{ Breastfeeding is essential } & P Value \\
\hline & Yes (\%) & No (\%) & Total (\%) & $P<0.05$ \\
\hline Christian & 307 (99.0) & $3(0.8)$ & $310(85.9)$ & \\
\hline Islam & $51(100.0)$ & 0 & $51(14.1)$ & \\
\hline Total & $358(99.2)$ & $3(0.8)$ & 361 & \\
\hline \multirow{2}{*}{ Ethnic group } & \multicolumn{3}{|c|}{ Breastfeeding is essential } & P Value \\
\hline & Yes (\%) & No $(\%)$ & Total (\%) & $P>0.05$ \\
\hline Yoruba & $227(99.1)$ & $2(0.9)$ & $229(58.3)$ & \\
\hline Hausa & $5(100.0)$ & 0 & $5(1.3)$ & \\
\hline Igbo & $155(99.4)$ & $1(0.6)$ & $156(39.7)$ & \\
\hline Fulani & $3(100.0)$ & 0 & $3(0.8)$ & \\
\hline Total & $390(99.2)$ & $3(0.8)$ & 393 & \\
\hline \multirow{2}{*}{ Education } & \multicolumn{3}{|c|}{ Breastfeeding is essential } & P Value \\
\hline & Yes (\%) & No $(\%)$ & Total (\%) & $P<0.05$ \\
\hline None & $5(100)$ & 0 & $5(1.3)$ & \\
\hline Pry Sch Uncompleted & $13(81.3)$ & $3(18.8)$ & $16(4.1)$ & \\
\hline Pry Sch Completed & $26(100.0)$ & 0 & $26(6.7)$ & \\
\hline Sec Sch Uncompleted & $13(100.0)$ & 0 & $13(3.4)$ & \\
\hline Sec Sch completed & $135(100.0)$ & 0 & 135(34.9) & \\
\hline Tertiary Ed Completed & $192(100.0)$ & 0 & $192(49.6)$ & \\
\hline Total & $384(99.2)$ & $3(0.8)$ & 387 & \\
\hline \multirow{2}{*}{ Profession } & \multicolumn{3}{|c|}{ Breast feeding is essential } & P Value \\
\hline & Yes (\%) & No $(\%)$ & Total (\%) & $P<0.05$ \\
\hline Housewife/Unemployed & $38(92.7)$ & $3(7.3)$ & $41(11.0)$ & \\
\hline Skilled & $303(100.0)$ & 0 & $303(81.2)$ & \\
\hline Unskilled & 20(100.0) & 0 & $20(5.4)$ & \\
\hline Others & $9(100.0)$ & 0 & $9(2.4)$ & \\
\hline Total & $370(99.2)$ & $3(0.8)$ & 373 & \\
\hline
\end{tabular}


Table 3. Respondents who practiced EBF for at least three months against their educational level.

\begin{tabular}{|l|c|c|c|c|}
\hline \multirow{2}{*}{ Education } & \multicolumn{3}{|c|}{ EBF For at Least Three Months } & P Value \\
\hline None & EBF Practiced (\%) & EBF Not Practiced & Total (\%) & P $<0.05$ \\
\hline Pry School Uncompleted & $2(40.0)$ & $3(60.0)$ & $5(1.3)$ \\
\hline Pry School Completed & $8(50.0)$ & $8(50.0)$ & $16(4.1)$ \\
\hline Sec School Uncompleted & $17(65.2)$ & $9(34.5)$ & $26(6.7)$ \\
\hline Sec School completed & $6(46.2)$ & $7(53.8)$ & $13(3.3)$ \\
\hline Tertiary Ed Completed & $130(94.9)$ & $7(5.1)$ & $137(35.2)$ \\
\hline Total & $185(96.4)$ & $7(3.6)$ & $192(49.4)$ \\
\hline
\end{tabular}

Table 4. Respondents who practiced exclusive breast feeding

\begin{tabular}{|l|c|c|c|}
\hline Respondents & Frequency & Total (\%) & $P<0.05$ \\
\hline EBF & 208 & 54.5 & \\
\hline No EBF & 174 & 45.5 & \\
\hline Total & 382 & 100 & \\
\hline
\end{tabular}

Table 5. Practice of EBF for at least three months against profession.

\begin{tabular}{l|c|c|c|c|}
\multirow{2}{*}{ Profession } & \multicolumn{3}{|c|}{ EBF For at Least Three Months } & P Value \\
\cline { 2 - 4 } & Yes (\%) & No (\%) & Total (\%) & P $<0.05$ \\
\hline Unemployed/Housewife & $27(65.9)$ & $14(34.1)$ & $41(10.9)$ \\
\hline Skilled & $291(95.4)$ & $14(4.6)$ & $305(81.3)$ \\
\hline Unskilled & $10(50.0)$ & $10(50.0)$ & $20(5.3)$ \\
Others & $8(8.8)$ & $1(11.1)$ & $9(2.4)$ \\
\hline Total & $336(89.6)$ & $39(10.4)$ & 375
\end{tabular}

The profession, the number of children, the religion and educational level were statistically significant among respondents who felt that breastfeeding was essential to the baby $(P<0.05)$ but not statistically significant for age and ethnic group. Practiced EBF for at least three months was statistically significant for education and profession ( $P$ $<0.05)$ but not statistically significant for age and ethnic group $(P>0.05)$. Practice difficulties were not statistically significant for number of children, marital status, mothers' age and ethnic group ( $P$ > $0.05)$ but were statistically significant for education and profession $(P<0.05)$.
The belief that colostrum was not good for the baby was not statistically significant for age, religion, ethnic group and the number of children $(P>0.05)$ but was statistically significant for education and profession $(P<0.05)$. Belief that sperm can get into the milk was statistically significant for age, religion, ethnic group, education, profession and the number of children $(P<0.05)$. The effectiveness of BFHI in the district served by the semi urban areas studied showed that $54.4 \%$ (208) of the respondents practiced EBF although this percentage included those who had practiced breastfeeding as well as those currently practicing EBF. 


\section{Discussion}

Almost fifty percent (49.4\%) of the respondents had completed their tertiary education. This was not surprising as the study populations were in a semi-urban area of the old capital of Nigeria. Education and profession were statistically significant for respondents that practiced EBF for at least three months $(P<0.05)$. In this study, respondents that were in the skilled profession included mothers who had completed their tertiary education. A study conducted in United Arab Emirates showed that the mother's education was significantly associated with exclusive breastfeeding [39]. On the contrary, a study conducted at The University of Benin Teaching Hospital, Nigeria did not show an association between maternal education and exclusive breastfeeding [29]. A separate study conducted in the savannah region of Nigeria showed that acquisition of secondary or post-secondary education was significantly associated with the practice of exclusive breastfeeding although for a shorter duration of time [40]. In another study in Calabar, Nigeria, the highest compliance to EBF was among self-employed mothers [41]. The study conducted in Calabar did not indicate the educational level of these self-employed mothers [41]. It could also be that those in paid employment had to stop breastfeeding because there were no accommodations to nurse their babies while at work.

In this study, age was not statistically significant with the practice of EBF. Similarly, The University of Benin Teaching Hospital Study did not show an association between maternal age and EBF [29]. In this study, marital status was not statistically significant for practice of EBF. A study conducted in Calabar, Nigeria found that in investigating compliance to EBF against marital status, compliance was highest amongst mothers that were married [41].

The belief that colostrum was not good was statistically significant for education $(P<0.05)$. In a separate study conducted in the savannah region of Nigeria, the mothers' educational level was asso- ciated with giving the child colostrum [40]. Mothers that had a low level of education discarded the colostrum [40].

The results of this study showed that for questions on knowledge, attitude and practice of EBF, the educational level of the mother and the professional level of the mother were consistently statistically significant $(P<0.05)$. However, the belief that sperm could get into milk was statistically significant for age, religion, ethnic group, education, profession and number of children $(P<0.05)$. Education of the mother has consistently been associated with better outcomes for the child. Mothers that were educated did not discard colostrum and they were more likely to have the correct knowledge on breast milk.

\section{Recommendations}

1. Health education targeted at women to correct the misconceptions about colostrum.

2. Health education correcting the beliefs about breastfeeding.

3. Employers should be encouraged to have day care centers for nursing mothers so that mothers who go back to paid employment do not have to stop breastfeeding.

4. A reevaluation of the $\mathrm{BFHI}$ starting from the needs analysis, designing, developing and implementation to determine the reasons for the decline in EBF after an initial upward trajectory should be conducted. 


\section{Conclusions}

The knowledge, attitude and practice of exclusive breastfeeding amongst mothers in the semi urban area of Lagos, Nigeria are statistically significantly affected by their socio demographic characteristics. The responses to knowledge questions on breastfeeding were significantly affected by their educational level, professional level, religion and by the number of children. The practice of EBF increased with increase in the level of mothers' education. Those with a higher educational level and those in skilled professions were more likely to practice EBF but for a shorter duration.

The predictive factors for breastfeeding exclusively are religion, education, profession and number of children. Age and ethnic group have no significant association with knowledge that breast milk was essential but age and ethnic group was significantly associated with the belief that sperm could get into the breast milk $(P<0.05)$. The effectiveness of the propagation of the BFHI appears to be stagnating and is not on an upward trajectory. Efforts can be made by maternity clinics, ante natal clinics and post natal clinics to educate mothers on exclusive breastfeeding at every contact mothers make with the clinic staff. Myths surrounding breastfeeding should be respectfully debunked.

\section{Acknowledgements}

I would like to acknowledge all the mothers who participated in the study. The author thanks the management of Lagos University Teaching Hospital, Nigeria my employer at the time of the study. I would also like to acknowledge Virginia Polytechnic Institute and State University's Open Access Subvention Fund (OASF).

\section{Conflict of Interest}

None 


\section{References}

1. World Health Organization (WHO) [Internet]. Geneva: WHO; 2014. E-Library of evidence for nutrition actions; Exclusive breastfeeding; 2014 Sept [cited 2014 Sept 1]; Available from: http://www.who.int/elena/titles/exclusive_breastfeeding/en/

2. Kramer MS, Kakuma R: Optimal duration of exclusive breastfeeding. Cochrane Database of Systematic Reviews 2002, Issue 1. Art. No.: CD003517. DOI: 10.1002/14651858. CD003517.

3. Fewtrell M. Wilson DC, Booth I, Lucas A: Six months of exclusive breastfeeding: how good is the evidence? BMJ, 2011, 342-349.

4. World Health Organization (WHO) [Internet]. Geneva: WHO; 2014. WHO (2002) report of the expert consultation on the optimal duration of exclusive breastfeeding. Geneva, Switzerland 28-30 march 2001. [cited 2014 Sept 1]; Available from http:// whqlibdoc.who.int/hq/2001/WHO_NHD_01.09.pdf?ua=1

5. World Health Organization (WHO) [Internet]. Geneva: WHO; 2014. Bulletin of the WHO (2008) Estimating child mortality due to diarrhea in developing countries. Geneva, Switzerland Sept 2008. [ cited 2014 Sept 1]; Available from http://www.who.int/ bulletin/volumes/86/9/0042-9686_86_07-050054-table-T3. html

6. World Health Organization (WHO) [Internet]. Geneva: WHO; 2014 Global Health Observatory: causes of child mortality by country, 2000 -2010. [cited 2014 Sept 3]; Available from http:// www.who.int/gho/child_health/mortality/mortality_causes_ text/en/

7. Quigley MA, Kelly YJ, Sacker A: Breastfeeding and hospitalization for diarrheal and respiratory infection in the United Kingdom Millennium Cohort Study. Pediatrics, 119, 2007: 837-842.

8. Walker, A: Breast milk as the gold standard for protective nutrients. J Pediatr, 2010, 156, S3-S7.

9. Jansen J, Weerth CD, Riksen-Walraven, JM: Breastfeeding and the mother-infant relationship-a review. Developmental Review, 2008, 28, 503-521.

10. Strathearn L, Mamun AA, Najman, JM, O'callaghan MJ: Does breastfeeding protect against substantiated child abuse and neglect? A 15-year cohort study. Pediatrics, 2009,123, 483-493.

11. Britton JR, Britton HL, Gronwaldt V: Breastfeeding, sensitivity, and attachment. Pediatrics, 2006, 118, 1436-1443.

12. Labbok MH: Effects of Breastfeeding on The Mother. Pediatr Clin North Am, 2001,48, 143-158.

13. Holdcroft A, Snidvongs S, Cason A, Doré CJ, Berkley, KJ: Pain and Uterine Contractions During Breastfeeding In The Immediate Post-Partum Period Increase With Parity. Pain, 2003, 104, 589-596.

14. Davanzo R, Brovedani P, Travan L:Integrating health care practices with the promotion of breastfeeding. J Pediatr Neonat Individual Med. 2014,3, (2): e030217.
15. United Nations Population Fund (UNFPA) [Internet]. Geneva: UNFPA, 2014 (UNFPA) 2013. UNFPA State of World Population 2013. Motherhood in Childhood: Facing the Challenges of Adolescent Pregnancy. [cited 2014 Sept 3]; Available from http://www.unfpa.org/webdav/site/global/shared/swp2013/ENSWOP2013-final.pdf

16. United Nations Children's Emergency Fund (UNICEF) [Internet]. Geneva: UNICEF, 2014 (UNICEF) 2013. UNICEF at a Glance: Nigeria.[cited 2014 Sept 3]; Available from http://www.unicef. org/infobycountry/nigeria_statistics.html

17. UNICEF 2014. Under Five Mortality Rankings. [Internet] [cited 2014 Sept 3]; Available from http://www.unicef.org/sowc2012/ pdfs/UNDER-FIVE-MORTALITY-RANKINGS.pdf

18. Organization of Petroleum Exporting Countries (OPEC) [Internet]. OPEC, 2014 (OPEC) 2013. 2013 OPEC Statistical Bulletin. [cited 2014 Sept 3]; Available from http://www.opec.org/opec_web/ static_files_project/media/downloads/publications/ASB2013. pdf

19. UNICEF. The State of the World's Children 1998; BFHI; Breast Feeding Breakthroughs. Available from [Internet] [cited 2014 Oct 10] http://www.unicef.org/sowc98/

20. UNICEF State of the World's Children. 2014. Table 2; Nutrition. [cited 2014 Oct 10] ; Available from [Internet] http://www.unicef. org/sowc2014/numbers/documents/english/EN- FINAL\%20 Table\%202.pdf

21. UNICEF 2014. Exclusive Breast Feeding Rates among children less than six months since 1990 plotted against timeline of key events to promote breast feeding during the same time period. [cited 2014 Oct 10] ;Available from [Internet] http://www.unicef. org/eapro/breastfeeding_on_worldwide_agenda.pdf

22. UNICEF. The Baby Friendly- Hospital Initiative. [Internet] [cited 2014 Sept 3];Available from http://www.unicef.org/programme/ breastfeeding/baby.htm\#10

23. UNICEF. Current status of baby friendly initiative [cited 2014 Sept 10]; Available from http://www.unicef.org/programme/ breastfeeding/assets/statusbfhi.pdf

24. Nikodem C, Schelke L, Enraght-Moony L, Hofmey RG 1995. Breastfeeding in crisis: Survey results of the baby-friendly hospital initiative. Curationis, 18, 39-42.

25. Gökçay G., Uzel, N., Kayatürk, F. \& Neyzi, O. 1997. Ten steps for successful breastfeeding: assessment of hospital performance, its determinants and planning for improvement. Child: care, health and development, 23, 187-200.

26. Montgomery DL \& Splett, P. L. 1997. Economic Benefit of BreastFeeding Infants Enrolled in WIC. J Am Diet Assoc. 97, 379-385.

27. Ball TM, Bennett DM: 2001. The economic impact of breastfeeding. Pediatr Clin North Am. 48, 253-262. 
28. Brewer-Asling, M, Magnus JH: A case study on the economic impact of optimal breastfeeding. Matern Child Health J, 2013,17, 9-13.

29. Eregie CO: Studies on exclusive breastfeeding: a report on associated factors in an African population. J Trop Pediatr. 1998, $44,172-173$

30. Ighogboja I, Odumodu C, Olarewaju R: Breastfeeding pattern in Jos, Nigeria, before baby-friendly hospital initiative. J Trop Pediatr 1996, 42, 178-179.

31. Dennis, CL: Breastfeeding Initiation and Duration: A 1990-2000 Literature Review. J Obstet, Gynecol, \& Neonatal Nurs. 2002, 31, 12-32.

32. Chye JK, Zain Z, Lim WL, Lim CT: Breastfeeding at 6 weeks and predictive factors. J Trop Pediatr. 1997, 43, 287-292.

33. Ukegbu A, Ukegbu P, Onyeonoro U, Ubajaka C: Determinants of breastfeeding patterns among mothers in Anambra State, Nigeria. SAJCH 2011,5, 112-116.

34. Bloss E, Wainaina F, Bailey RC: Prevalence and predictors of underweight, stunting, and wasting among children aged 5 and under in western Kenya. J Trop Pediatr. 2004, 50, 260-270.

35. Black RE, Allen LH, Bhutta ZA, Caulfield LE, de Onis M, Ezzati M, Mathers C, Rivera J: Maternal and child undernutrition: global and regional exposures and health consequences. The lancet, 2008, 371, 243-260.

36. Wamani H. Åstrøm AN, Peterson S. Tumwine JK, Tylleskär T: Predictors of poor anthropometric status among children under 2 years of age in rural Uganda. Public Health Nutrition, 2006, 9, 320-326.

37. Greer FR, Sicherer SH, Burks AW: Effects of early nutritional interventions on the development of atopic disease in infants and children: the role of maternal dietary restriction, breastfeeding, timing of introduction of complementary foods, and hydrolyzed formulas. Pediatrics, 2008, 121, 183-191.

38. Adeyemo A, Sodeinde $O$, Gbadegesin R, Ademowo $O$ : Breastfeeding and bloody diarrhoea in young children in Ibadan, Nigeria. J Trop Pediatr. 1997, 43, 235-236.

39. Al-mazroui M, Oyejide C, Bener A, Cheema M: Breastfeeding and supplemental feeding for neonates in Al-Ain, United Arab Emirates. J Trop Pediatr. 1997, 43, 304-306.

40. Okolo S, Adewunmi Y, Okonji M: Current breastfeeding knowledge, attitude, and practices of mothers in five rural communities in the Savannah region of Nigeria. J Trop Pediatr. 1999, 45, 323-326.

41. Ekanem I, Ekanem A, Asuquo, A, Eyo V: Attitude of working mothers to exclusive breastfeeding in Calabar municipality, Cross River State, Nigeria. J Food Res. 2012, 1, 71.

\section{Comment on this article:}

\section{f) $[$ in $8+\mathbf{S} P$}

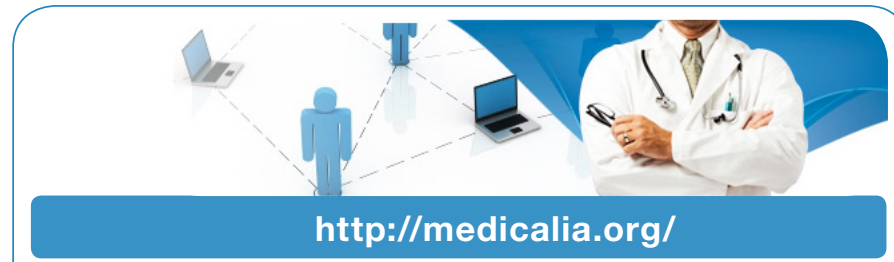

Where Doctors exchange clinical experiences, review their cases and share clinical knowledge. You can also access lots of medical publications for free. Join Now!

\section{Publish with iMedPub}

\section{http://www.imed.pub}

International Archives of Medicine is an open access journal publishing articles encompassing all aspects of medical science and clinical practice. IAM is considered a megajournal with independent sections on all areas of medicine. IAM is a really international journal with authors and board members from all around the world. The journal is widely indexed and classified Q1 in category Medicine. 